\title{
O ENSINO DE LÍNGUAS ESTRANGEIRAS UTILIZANDO TEXTOS BÍBLICOS
}

\author{
Núbia Andréa da Costa Silva ${ }^{1}$
}

RESUMO: Este artigo teve como objetivo estudar a importância de se utilizar os textos bíblicos para o ensino-aprendizagem da língua inglesa na educação infantil e ensino fundamental. A Bíblia traz uma riqueza linguística, histórica e, também, agrega valores morais e espirituais imprescindíveis para uma formação integral do ser humano. Há um conceito geral na atual sociedade quanto a importância do domínio de outros idiomas, em especial do inglês, para o alcance de sucesso profissional, o que contribui para que o interesse pelo ensino-aprendizagem dessa língua seja cada vez mais efetivo uma vezo interesse é o que incentiva a construção do conhecimento mas ao mesmo tempo não se pode negar que há uma real e urgente necessidade de se despertar nos educandos uma reflexão a respeito de valores como o respeito a Deus, aos outros e por si mesmo. Para a confecção deste artigo optou-se por uma pesquisa básica e descritiva, pela abordagem qualitativa e pelos métodos hipotético e dedutivo. No estudo de caso, realizado com crianças da Escola Classe $116 \mathrm{em}$ Santa Maria, Distrito Federal, foi mostrado o desenvolvimento de crianças a partir de 6 anos de idade com acesso a este ensino e que obtiveram um alto nível de desenvolvimento não só no inglês, mas também no raciocínio lógico e na socialização, devido à associação do ensino teórico e a prática real utilizando inúmeros recursos como a contação dehistória em forma de teatro e a musicalização. Percebeu-se que aprender inglês por meio dos textos bíblicos, contribui para a excelência na aprendizagem, e, ao mesmo tempo, promove a educação cristã. Concluiu-se que a referida técnica didático-pedagógica é efetiva e deve ser sempre, melhorada.

Palavras-chaves: Língua Inglesa. Bíblia. Crianças. Educação. Escola Classe iı6 em Santa Maria-DF.

\section{INTRODUÇÃO}

Este artigo estudou a importância de se utilizar os textos bíblicos para o ensinoaprendizagem de línguas estrangeiras na educação infantil e ensino fundamental.

\footnotetext{
${ }^{I}$ Licenciatura em Pedagogia- ICSH, Professora de Educação Infantil, alfabetização, inglês, cooedenação escolar, supervisão de equipe, planejamento pedagógico, projetos educacionais e sociais e colaboração em materiais pedagógicos.
} 
De forma clara e objetiva, buscou-se por meio desse artigo a demonstração de ações que podem potencializar o ensino e ajudar no desenvolvimento do educando, tendo em vista que atualmente na sociedade aprender outro idioma traz benefícios, pois esse domínio permite que o educando acesse outro patamar em sua carreira profissional e, também, pode promover realizações na vida pessoal.

Sabe-se também que essa mesma sociedade necessita formar profissionais que tenham não só domínio acadêmico, mas moral para exercer suas funções com honestidade, senso de justiça, competência e além disso ainda necessita de cidadãos que se preocupem com o outro, que conhecem os seus direitos e sabem muito bem cada dever que lhe compete.

A Bíblia traz uma riqueza linguística, histórica e, também, agrega valores morais eespirituais imprescindíveis para formação integral do ser humano. Há uma percepção na atual sociedade quanto a importância do domínio de outros idiomas,em especial do inglês, para o alcance de sucesso profissional, o que contribui paraque o interesse pelo ensino-aprendizagem dessa língua seja cada vez mais efetivo. O interesse é o que incentiva a construção do conhecimento, mas ao mesmo temponão se pode negar que existe a necessidade de se despertar nos educandos umareflexão a respeito de valores como o respeito a Deus, aos outros e por si mesmo.

Para a elaboração deste artigo escolheu-se uma pesquisa básica e descritiva, optandose pela abordagem qualitativa e pelos métodos hipotético e dedutivo. No estudo de caso realizado com crianças da Escola Classe iı6 em Santa Maria, Distrito Federal, no Brasil, foi mostrado o desenvolvimento de crianças a partir de 6 anos de idade com acesso a este ensino e que obtiveram relevante nível de desenvolvimento não só no inglês, mas também no raciocínio lógico e na socialização, devido à associação do ensino teórico e a prática real utilizando inúmeros recursos como a contação de história em forma de teatro e a musicalização.

De início foram abordados o ensino e a aprendizagem de línguas estrangeiras por meio da Bíblia. Em seguida, o ensino religioso confessional nos cursos de língua estrangeira. Depois, a utilização dos cursos dessas línguas para incentivar o interesse nos ensinamentos religiosos por meio dos textos sagrados, em crianças nacitada escola. Por fim, foram tecidas considerações finais. 


\section{A APRENDIZAGEM E O ENSINO DE LÍNGUAS ESTRANGEIRAS PORMEIO DA BIBLIA}

O ensino religioso é uma disciplina da educação básica Brasileira que tem como foco de ensino os fundamentos, costumes e valores das religiões. É amparada legalmente pela Constituição Federal de 1988 no artigo 210: "O ensino religioso, de matrícula facultativa, constituirá disciplina dos horários normais das escolas públicasde ensino fundamental”. (BRASIL, 2019)

Para Pontes (2017), o ensino religioso confessional é uma disciplina em que as aulas são ministradas a partir de uma religião específica. No dia 27 de setembro de 2017 no Supremo Tribunal Federal (STF), votaram a favor de permitir o modelo confessional de ensino religioso Cármen Lúcia, Alexandre de Moraes, Edso Fachin, Gilmar Medes, Dias Toffoli e Ricardo Lewandoswski permitindo que em escolas públicas o ensino religioso possa ser dessa forma.

A obrigatoriedade é para as escolas de ensino fundamental, mas é facultativa para os alunos, como previsto no art. 33 da LDB (Lei de Diretrizes e Bases):

Art. 33. O ensino religioso, de matrícula facultativa, é parte integrante da formação básica do cidadão e constitui disciplina dos. horários normais das escolas públicas de ensino fundamental, assegurado o respeito à diversidade cultural religiosa do Brasil, vedadas quaisquer formas de proselitismo. (BRASIL, 2019)

Pode-se observar a presença do ensino religioso no Brasil desde o período colonial com os Jesuítas, que tinham foco no catolicismo e para eles, a conversão era alcançada pela via da Educação (CORDEIRO, 20ı6).

No período imperial a Religião Católica Romana já era a religião oficial do império eo Ensino Religioso era ministrado mais de forma ideológica, uma vez que a igreja tinha o domínio econômico e cultural nesse período. Já na República o Ensino da Religião Católica Romana passa por uma crise em I89ı com o pedido de separaçãodo Estado e da Igreja. (DA COSTA, 20II)

"Será leigo o Ensino ministrado nos estabelecimentos oficiais de ensino" (PCN: ER, 2004. p. 14).

A partir dessa primeira orientação para a Educação Brasileira dada pela Constituição da República, o Ensino Religioso só deveria ser ministrado em estabelecimentos específicos 
e não mais nas mantidas pelo Poder Público. Tal orientação causou grande discussão a respeito do tema, chegando até a levantar a possibilidade de exclusão do ensino religioso no texto da Constituição de I89I, devido a laicidade. (DA COSTA, 20II)

Em 1931 a reforma Francisco Campos levantou a questão de se pensar no Ensino Religioso em caráter facultativo, por meio do decreto de 30 de abril de I93ı e na Constituição de 1934 ele passa a ser admitido como tal no artigo 153 que diz:

O ensino religioso será de frequência facultativa e ministrado de acordo comos
princípios da confissão religiosa do aluno manifestada pelos pais ou responsáveis e
constituirá matéria dos horários nas escolas públicas primárias, secundárias,
profissionais e normais. (BRASIL, 2019)

Até os dias atuais ainda permanece essa condição de caráter facultativo para o ensino religioso e a Lei de Diretrizes e Bases da Educação Nacional no 9.475/97, passou a tratar o Ensino Religioso como área do conhecimento, com metodologia específica horários préestabelecidos em sala de aula, conteúdos, avaliação, objeto de investigação e professores especializados. (BRASIL, 2018)

Em 2010 a Procuradoria Geral da República (PGR) moveu uma ação pois entendia que o ensino religioso só poderia ser oferecido se o conteúdo programático dadisciplina consistisse na exposição “das doutrinas, práticas, histórias e dimensãosocial das diferentes religiões”, sem que o professor privilegiasse nenhum credo,mas em 2017 o Supremo Tribunal Federal (STF) julgou a ação improcedentepermitindo que o ensino religioso nas escolas públicas permanecesse estritamentefacultativo, sendo ofertado dentro do horário normal de aula e autorizou também acontratação de representantes de religiões para ministrar as aulas. (BRASIL, 2019) O Ensino Religioso contribui na formação integral do aluno, amplia a reflexão,direciona a um agir social, orientando o educando a transformar suas relaçõesinterpessoais, observando a prática do respeito a Deus e ao outro.

O Parâmetro Curricular do Ensino Religioso esclarece o objetivo do ER

Objetivo do Ensino Religioso: “[...] - subsidiar o educando na formulação do questionamento existencial, em profundidade, para dar sua resposta devidamente informados; - refletir o sentido da atitude moral, como consequência do fenômeno religioso e expressão da consciência e da resposta pessoal e comunitária do ser humano [...]”. (FONAPER. 1998. p. 30-3I).

Por meio do ensino religioso a criança tem a oportunidade de conhecer Deus, em primeiro lugar e esse conhecimento trará benefícios em todas as esferas de suavida, 
tendo em vista que o ser humano tem uma necessidade de adoração. Esse ensino também contribuirá para a formação moral do educando, pois estudará princípios e verdades bíblicas que o levarão a identificar os fundamentos do conhecimento e assim poderão refletir sobre suas ações positivamente.

E a legislação Brasileira tem avançado no reconhecimento da importância dessa área do conhecimento, respeitando a individualidade do aluno e de sua família, mas entendendo que a escola também educa a alma, contribui na formação do caráter, orienta as ações éticas, morais para a construção de uma sociedade com menos problemas de violências e injustiças e o ER é uma importante ferramenta para se alcançar positivamente esses resultados.

O avanço no reconhecimento do Estado quanto a necessidade dessa área do conhecimento se deu através do diálogo entre as confissões cristãs o que possibilitou a construção de uma identidade pedagógica para o ER que tem como pressuposto fundamental a formação básica do cidadão.

Hoje caracterizado como um componente curricular, está organizada nos PCNER (2000), que o trata como área de conhecimento, atribui-lhe um caráter pedagógico como o de qualquer outra disciplina do currículo básico da educação nacional.

Trata-se de uma proposta inovadora para o Ensino Religioso que tem como principal característica a mudança do Ensino Religioso do campo religioso para o campo secular. Apresenta essa modalidade de ensino com caráter científico, epistemológico destituído de proselitismo. (TOLEDO; AMARAL, 2005, p. 4)

O ER, portanto, contribui de forma efetiva na formação de uma sociedade mais consciente de seus direitos e deveres, sendo mais bem instruída nos aspectos espirituais que fazem parte na formação do homem, uma vez que essa área norteará o educando a ter conhecimento de justiça, cultura e paz entre os indivíduos.

\section{O ENSINO RELIGIOSO CONFESSIONAL NOS CURSOS DE LÍNGUAS ESTRANGEIRAS}

A procura por cursos de línguas é relevante no Brasil e no mundo. Crianças, adolescentes, jovens, adultos e idosos procuram aprender as línguas estrangeiras do mundo inteiro. Esse interesse é um importante fator para a aprendizagem dos estudantes e, nesse momento, se abre uma "porta" para qualquer tipo de ensinamento, e, é claro, para o ensino de qualquer língua estrangeira. 
$\mathrm{Na}$ pesquisa do Instituto de Pesquisa Data Popular, que trata das Demandas de Aprendizagem do Inglês no Brasil (2014), que foi elaborado com exclusividade parao British Council, fica bem claro que o Brasileiro tem a consciência da importância desta área do conhecimento mas tem dificuldade de acesso a ela, o que limita a maioria a se declarar com o nível de conhecimento apenas básico:

\begin{abstract}
A busca por uma escola de idiomas é a principal forma de suprir a necessidade do inglês fora da formação básica. Escolas de idiomas foram apontadas como a solução mais buscada em $87 \%$ das respostas. As demais respostas se dividem entre a procura por professores particulares (6\%), cursos na empresa $(3 \%)$ ou na escola (Centro de Estudo de Línguas) (2\%), cursos online (1\%) ou através de fascículos e apostilas (I\%). Mesmo entre quem já fez ou ainda faz algum curso de inglês, o nível de conhecimento atual declarado é o básico. (BRITISH COUNCIL, 20I4, p. 5)
\end{abstract}

E pertinente lembrar que muitas pessoas têm desejo de aprender inglês mas passam por muitas dificuldades uma vez que a língua inglesa possui uma cultura, história e estrutura totalmente diferente da língua portuguesa. O português surgiu através do Latim, já o inglês veio do Anglo-saxão (VENTURINI, 2017), idiomas totalmente diferentes em todos os sentidos. Daí a necessidade de se proporcionarao educando um contato com o idioma o mais cedo possível pois a fluência só vem através da experiência com o idioma.

As práticas didático-pedagógicas usadas nas aulas de línguas, geralmente são mais variadas e despertam mais interesse por parte dos alunos. Com o atual sistema globalizado, não é difícil encontrar literatura, mídias, games, aplicativos ou músicas que façam parte do próprio dia-a-dia dos alunos em inglês. O que torna o ensino da língua muito mais atraente e efetivo. Um exemplo é a plataforma do Duolingo, um aplicativo muito utilizado no mundo inteiro para o ensino de idiomas que agora traz uma versão para sala de aula, dando suporte interativo para a dinâmica de estudos do idioma.

Duolingo para Escolas: Agora a plataforma de aprendizado de idiomas mais popular do mundo está disponível para a sala de aula. Milhares de professores já estão usando para elevar as suas aulas. (DUOLINGO, 2018)

É nesse campo que o ensino religioso pode ser ensinado, já que existe o interesse do estudante pela língua escolhida e, neste momento, também se ensina os conteúdos religiosos de opção. Isso também, é claro, pode ser feito para a aprendizagem do Ensino Religioso Confessional.

De fato, pode-se ter dois ensinamentos utilizando o mesmo tempo, o mesmo espaço 
e o mesmo professor para ensinar dois conteúdos e isso é muito interessante paraos estabelecimentos de ensino, mais notadamente, os religiosos. E para o Ensino Religioso Confessional isso também é pertinente, pois, nesse caso, já existe uma religião específica para o estabelecimento de ensino.

O Ensino Religioso também utiliza diversas atividades de ensino com a utilização de várias práticas distintas, e, que, também despertam interesse, como o uso do teatro, da música, da expressão corporal através da dança, dinâmicas variadas que incentivam o aluno a participar da história e assim potencializar o ensino.

Esta coincidência de ensino-aprendizagem é um fator positivo para o sucesso de se usar o ensino de uma dada língua estrangeira e, ao mesmo tempo, um conhecimento religioso, pois podem se utilizar o teatro, por exemplo, para uma peça de uma parte de um texto bíblico em uma peça, usando uma língua estrangeira.

Não se pode falar de ER sem nos referirmos a Bíblia Sagrada, pois nela encontramse instruções muito claras quanto a importância do ensino não somente espiritual, mas para a vida, englobando muitas áreas do conhecimento. Apegue-seà instrução, não a abandone; guarde-a bem, pois dela depende a sua vida. (BIBLIA ONLINE, 2018).

Questões que englobam matemática, geografia, história, ciências são citadas na Bíblia e podem ser utilizadas como exemplos para potencializar o ensino em sala de aula. Além, é claro, do ensino da língua propriamente dita. Em português como primeira língua pois há uma diversidade linguística que é apropriada para educandosque necessitam estudar diversas figuras de linguagem.

De acordo com citação do site Verdade Viva:

A linguagem da Bíblia tem três formas distintas - Figurativa, Simbólica e Literal. Linguagem Figurativa Expressões como «não endureças o teu coração» e «deixai que os mortos enterrem os seus mortos», são FIGURATIVAS e o seu significado é tornado claro pelo contexto. Linguagem Simbólica Notemos os seguintes exemplos: A descrição da «GRANDE ESTÁTUA» do sonho de Nabucodonosor; «As quatro bestas selvagens» de Daniel; «Cristo no meio dos sete castiçais» Esta linguagem simbólica é explicada ou no próprio texto ou em algum outro lugar da Bíblia. Linguagem Literal A Bíblia deve ser interpretada de acordo com as normas da gramática e da retórica ou oratória. Isto significa que devemos ler a Bíblia como lemos qualquer outro livro, deixando que ele diga o que tem a dizer, sem alegorizar ou espiritualizar o seu significado. $O$ falso método de interpretar a Bíblia é que tem conduzido a tantas seitas e denominações. (ESTEVES, 2018)

A diversidade de gêneros textuais ali encontradas também contribuem para o 
desenvolvimento das habilidades que se relacionam à leitura. Ao mencionarmos gêneros textuais estamos nos referido às diversas formas de comunicação escrita, que podem estar em cartões, telegramas, contos, fábulas, anedotas, poemas, cartazes, textos científicos que tem uma função específica, para um público específico e têm características próprias.

Os gêneros que podem ser encontrados na Bíblia são: jurídico, narrativo (Epopéia, Épico, Tragédia e Romance), poesia, profético, apocalíptico, sapiencial, evangelhos, epistolar, genealogias, hinos e cânticos e apocalíptico. Observa-se, portanto, uma riqueza de gêneros literários que constituem um fator muito importante para que o estudo da Bíblia tenha o seu lugar na formação do educando.

Se por um lado pode-se observar todos estes aspectos com relação a língua portuguesa, não seria menos efetiva por outro lado com relação a qualquer outro idioma, uma vez que temos a tradução desse livro para 2935 idiomas, de acordo com a SBB (Sociedade Bíblica do Brasil): As Escrituras Sagradas estão disponíveis para 2.935 idiomas falados por 6,039 bilhões de pessoas. Vamos destacar o idioma inglês, objeto de estudo específico desse artigo.

Observado portanto essas duas vertentes: o ER por meio da Bíblia e o Ensino do Inglês, propõe-se nesse artigo a junção dessas duas áreas de estudo que podem potencializar o ensino-aprendizagem e levar os educandos a uma reflexão didática, moral e espiritual, que pode acrescentar muito em suas vidas acadêmicas e pode levá-los a um futuro com maiores possibilidades de sucesso. Uma vez que se propõe uma educação com princípios morais e espirituais, conduz-se o educando a pensar em suas responsabilidades enquanto cidadão e analisar suas escolhas, e suas atitudes em seu cotidiano, que refletirão em seus resultados.

\section{PROCEDIMENTOS METODOLÓGICOS}

Para a elaboração deste artigo escolheu-se por uma pesquisa básica e descritiva, pela abordagem qualitativa e pelos métodos hipotético e dedutivo. Foi analisado um estudo de caso, realizado com crianças da Escola Classe ir6 em Santa Maria, Distrito Federal, no qual foi observado o desenvolvimento de crianças a partir de 6 anos de idade com acesso a este ensino e que obtiveram um elevado nível de desenvolvimento não só no inglês, mas também no raciocínio lógico e na socialização, devido à associação do ensino teórico e a prática real utilizando inúmeros recursos como a contação de história em forma de teatro e a 
musicalização.

Foram obtidas informações provenientes de revisão bibliográfica em visitas a sítios eletrônicos governamentais e de plataformas de trabalhos acadêmicos, além de livros.

\title{
4 A UTILIZAÇÃO DOS CURSOS DE LÍNGUAS ESTRANGEIRAS PARA INCENTIVAR O INTERESSE NOS ENSINAMENTOS RELIGIOSOS POR MEIO DA BÍBLIA, EM CRIANÇAS DA ESCOLA CLASSE 16 DE SANTA MARIA DF
}

\section{Descrição da escola:}

\author{
ESCOLA CLASSE II6 DE SANTA MARIA
}

\section{Localização:}

QUADRA II6 CONJUNTO M LOTE or. SANTA MARIA-DF

\section{Breve histórico:}

A escola iniciou suas atividades em o7 de março de 1994, atendendo a comunidade, prioritariamente local, com I2 salas de aula com aproximadamente ı.6oo alunos, distribuídos entre a $8^{\mathrm{a}}$ série e Ensino Especial. Sua primeira diretora foi a professora Maria Rita Vieira Ferreira.

Em 1995, a citada escola recebeu uma ampliação de 9 salas de aula e em 1996 foi implantada a Gestão Democrática. Em 2002 foi credenciada oficialmente pelo Ministério da Educação era - MEC, tendo como parceiro o Instituto Escola Brasil do Banco Real $\mathrm{ABN}$, o qual vem trazendo algumas melhorias físicas para a escola, que hoje atende a r.ıo alunos.

Em 2008 a Secretaria de Estado da Educação do Governo do Distrito Federal SEEDF/GDF implantou o sistema de Gestão Compartilhada e a escolha dos gestores se deu por meio de eleição, sistema que em vigor até os dias de hoje. Ao longo dos anos a escola foi se adaptando às necessidades dos alunos, recebendo um espaço para recreação, uma sala de apoio psicopedagógico, um laboratório de Informática, uma sala de recursos para atendimento aos estudantes ANEE'S (Alunoscom Necessidades Educacionais Especiais), entre outros espaços, além de estrutura necessária para contribuir na construção da cidadania, valorização do lúdico, do civismo, das artes e do respeito às diferenças humanas. 


\section{Missão da escola:}

Buscar procedimentos metodológicos pedagógicos que possam ir ao encontro da perspectiva de inclusão social, no sentido de se promover uma educação "libertadora", levando em consideração as especificidades de cada estudante.

Número de professores:

67 professores

Qualificação dos professores:

Nível Superior e Pós-Graduação

Número de alunos na escola:

700 ALUNOS

Manutenção:

PDAF - ENFRAGET (Empresa da Secretaria de Educação)

Número de alunos atendidos na pesquisa:

87 alunos das turmas do ensino integral, sendo 37 no matutino e 50 no vespertino.

\section{Recursos utilizados:}

Caderno de atividades, lápis de escrever, lápis de colorir, giz de cera, cola, tesoura, quadro, caixa de som, cenário, microfones, figurino.

\section{Procedimento metodológico de pesquisa:}

Apresentação do idioma inglês por meio da história bíblica da criação do mundo, registrada em "Gênesis I”. Inicialmente, para despertar a atenção dos alunos foi apresentado o conteúdo por meio da contação da história, utilizando-se linguagem adequada e com o uso de recursos visuais.

Posteriormente, para o desenvolvimento da capacidade de concentração dos alunos, descreveu-se a sequência dos fatos, motivando-os à memorização da história com a utilização das línguas Inglesa e Portuguesa. Os trechos da história bíblica foram revisados a 
cada aula, desde o começo, o que possibilitou uma maior familiarização com o vocabulário.

Em todas as aulas os alunos reproduziram a história recebida no Caderno de Construção, utilizando as técnicas de colagem, de pintura, de pesquisas e de desenhos, o que aumentou os seus vocabulários e desenvolveu habilidades motoras.

Durante o processo de ensino da história, foi também trabalhado, paralelamente, a interpretação dos textos sobre história, considerando o fato de que desde o início das aulas, os alunos foram motivados a montar o Teatro da Criação, no qual cada estudante assumiu o seu papel na história, ensaiando a sua apresentação para a sua família, juntamente com seus colegas, em um dia específico, por meio da teatralização.

Nessa apresentação, foi trabalhada a autoestima dos alunos, a interpretação, a entonação de voz, a postura em cena e o respeito aos colegas em suas apresentações. Enfim, muitas atividades educacionais voltadas ao desenvolvimento da socialização, que é primordial para o desenvolvimento acadêmico dos estudantesde forma integral. Além da apresentação para os familiares, os educandos também levaram seus livros poup up para casa e puderam compartilhar com seus amigos e familiares seus conhecimentos, o que potencializou a aprendizagem.

\section{CONSIDERAÇÕES FINAIS}

O curso de Inglês por meio de textos bíblicos contribuiu de maneira efetiva para o desenvolvimento satisfatório dos alunos que participaram da pesquisa, não somente no ensino do idioma, propriamente dito, mas também, despertando-os para o desenvolvimento de habilidades ligadas a outras áreas do conhecimento, como o do raciocínio lógico e o da socialização, por exemplo.

O curso teve um importante papel na educação desses alunos, pois foi além da sua proposta inicial, trouxe esperança para muitas crianças que possuem baixa renda e dificuldades de acesso ao conhecimento. Desse modo, tiveram a oportunidade de conhecer trechos de histórias bíblicas, que rendeu um novo olhar a respeito de si mesmos, compreendendo que, mesmo tão pequenos, puderam ser atores principais e participar de apresentações para toda a comunidade acadêmica local e seus familiares, o qual, em muitos casos, teve papel fundamental no tratamento da baixa autoestima e receios de que alguns 
alunos tivessem dificuldades de apresentarem seus trabalhos em público. O que fizeram com visível naturalidade e espontaneidade. Os resultados foram expressivos, revelando a capacidade individual e desenvolvendo o trabalho coletivo, no qual os alunos demonstraram dedicação, cuidados com o material e foram incentivados a terem disciplina e a trabalharem em equipe.

As famílias que assistiram a apresentação ficaram muito encantadas com o resultado, pois foi algo inusitado ao qual não estão acostumadas. Muitos se emocionaram ao verem seus filhos falando em outro idioma e perceberam que esteé um passo importante para que seus filhos se tornem cidadãos bem sucedidos,pois reconheceram a necessidade de uma formação integral, com familiarização de outros idiomas e também reconheceram a importância de se apresentar os princípios da palavra de Deus a esta geração que tem tantos desafios morais para enfrentarem em uma sociedade com altos problemas sociais, econômicos e culturaisrelevantes.

\section{REFERÊNCIAS}

BÍBLIA ONLINE. Provérbio 4:13. Disponível em: https://www.bibliaonline.com.br/ acf/busc $\mathrm{C}_{3 \%} \%$ Agrbios+4\%3Ai3. Acessoem: 21 jul. 2019.

BRASIL. Planalto. Constituição Federal de 1934. Disponível em: http://www.planalto.gov.br/ccivil_03/Constituicao/Constituica034.htm. Acesso em: I9 jul. 2019 .

BRASIL. Planalto. Constituição Federal de 1988. Disponível em: 〈http://www.planalto.gov.br/ccivil_03/constituicao/constituicaocompilado.htm〉. Acesso em: 20 jul. 2019.

BRASIL. Planalto. Lei de Diretrizes e Bases. Lei $\mathrm{n}^{\circ}$ 9.395/1996. Disponível em: http://www.planalto.gov.br/ccivil_03/leis/L9394.htm. Acesso em: 20 jul. 2019.

BRASIL. Planalto. Lei de Diretrizes e Bases. Lei $n^{\circ}$ 9.395/r996. Disponível em: http://www.planalto.gov.br/ccivil_03/leis/L9394.htm. Acesso em: I8 jul. 2019.

BRASIL. Superior Tribunal Federal - STF. STF conclui julgamento sobre ensino religioso nas escolas públicas. 2017. Disponível em: http://www.stf.jus.br/portal/cms/verNoticiaDetalhe.asp?idConteudo=357099. Acesso em: I8 jul. 2019. 
BRITISH COUNCIL. Demandas de Aprendizagem de Inglês no Brasil, elaborado com exclusividade para o British Council, pelo Instituto de Pesquisa Data Popular. red. São Paulo, 2014.

CORDEIRO, Tiago. A grande aventura dos jesuítas no Brasil. i ed. São Paulo: Planeta, 2016.

DA COSTA, Antônio Max Ferreira. Um breve histórico do ensino religioso na educação brasileira. 2011. Disponível em: https://cchla.ufrn.br/humanidades20o9/Anais/GTo7/7.4.pdf. Acesso em: 19 jul. 2019.

DUOLINGO. Aprenda idiomas de graça. Disponível em: https://www.duolingo.com. Acesso em 20 jul. 2019.

ESTEVES, Augusto. A Bíblia Sagrada. 2018. Disponível em: https://www.verdade-viva.net/a-biblia-sagrada. Acesso em: 22 jul. 2019.

PCNER - Parâmetros Curriculares Nacionais para o Ensino Religioso. Fórum Nacional Permanente do Ensino Religioso - FONAPER. 3 ed. São Paulo: MundoMirim, 2009.

PONTES, Felipe. Supremo autoriza ensino religioso confessional nas escolas públicas. Disponível em:

http://agenciabrasil.ebc.com.br/educacao/noticia/2017-09/supremo-autoriza-ensino-r eligioso-confessional-nas-escolas-publicas. Acesso em: 20 jul. 2019.

SBB - Sociedade Bíblica do Brasil. Escrituras Sagradas já foram traduzidas para 2.935 idiomas. 2016. Disponível em: https://mail.google.com/mail/u/o/\#inbox/FMfcgxvzLWxTdrDHhnRrNNnKPKfQwsW M.Acesso em: 2 nov. 2018.

TOLEDO. Cézar de Alencar Arnaut; AMARAL, Tânia Conceição Iglésias. Análise dos Parâmetros Curriculares Nacionais para o ensino religioso nas escolas públicas. 2005 . Disponível em: http://www.periodicos.udesc.br/index.php/linhas/article/view/r248. Acesso em: 2r jul.2019.

VENTURINI, Laercio. Origem e desenvolvimento da língua inglesa. Disponível em: https://www.linkedin.com/pulse/origem-e-desenvolvimento-da-l\% $\mathrm{C}_{3} \% \mathrm{ADngua}$-ingles a-laercio-venturini. Acesso em: 22 jul. 2019. 